\title{
Balkanologie
}

Balkanologie Revue d'études pluridisciplinaires

Vol. XIII, $n^{\circ}$ 1-2 | 2011

Volume XIII Numéro 1-2

\section{Pavlović (Srdja), Balkan Anschluss. The Annexation of Montenegro and the Creation of the Common South Slavic State}

West Lafayette : Purdue University Press, 2007, 228 p.

Patrick Michels

\section{CpenEdition}

Journals

Édition électronique

URL : http://journals.openedition.org/balkanologie/2319

DOI : 10.4000/balkanologie.2319

ISSN : 1965-0582

Éditeur

Association française d'études sur les Balkans (Afebalk)

Référence électronique

Patrick Michels, "Pavlović (Srdja), Balkan Anschluss. The Annexation of Montenegro and the Creation of the Common South Slavic State », Balkanologie [En ligne], Vol. XIII, n 1-2 | 2011, mis en ligne le 16 décembre 2011, consulté le 17 décembre 2020. URL : http://journals.openedition.org/balkanologie/ 2319 ; DOI : https://doi.org/10.4000/balkanologie.2319

Ce document a été généré automatiquement le 17 décembre 2020.

(c) Tous droits réservés 


\section{Pavlović (Srdja), Balkan Anschluss.} The Annexation of Montenegro and the Creation of the Common South Slavic

\section{State}

West Lafayette : Purdue University Press, 2007, 228 p.

\section{Patrick Michels}

\section{RÉFÉRENCE}

Pavlović (Srdja), Balkan Anschluss. The Annexation of Montenegro and the Creation of the Common South Slavic State, West Lafayette: Purdue University Press, 2007, 228 p.

1 S. Pavlovic, politologue, co-fondateur de Spaces of Identity (revue en ligne), s'intéresse aux prémices de l'inclusion du Monténégro dans le Royaume des Serbes, Croates et Slovènes. Il y dresse une vision critique de l'histoire politique et identitaire de la population du Royaume du Monténégro à la fin XIX ${ }^{\text {ème }}$ et au début XX ${ }^{\text {ème }}$ siècle.

Dès l'introduction, il affirme que le droit à l'autodétermination, principe à la base des compromis qui ont participé à la création des États post-impériaux de l'Europe du Centre et des Balkans, a été refusé aux Monténégrins. Cependant, tout comme sur leur identité nationale, les Monténégrins sont divisés sur la terminologie à employer sur la décision de l'Assemblée de Podgorica du 25 novembre 1918 (annexion ou unification). Cette décision, qui proclame l'union du Monténégro à la Serbie, a fait, et fait toujours, l'objet de virulentes disputes quant à «la légalité de l'Assemblée, la légitimité de sa résolution et sa représentativité de la volonté populaire des Monténégrins » (pp. 3, 13-22). Ce débat déborde sur l'identité nationale des Monténégrins, trop facilement «assimilés» aux Serbes, malgré la résistance de leur Église orthodoxe, et le «Soulèvement de Noël 1919 » (lutte armée de janvier 1919). De fait, «l'intégration » du Monténégro à la Serbie s'appuie sur la serbité supposée des Monténégrins. La 
revendiquer permet d'évoquer une prétendue continuité temporelle et culturelle de la nation serbe. Cependant, l'identification monténégrine aux Serbes a lieu avant la conceptualisation de la nation et sa contextualisation montre qu'elle se réfère à la sudslavité, à la coalition anti-ottomane et à la chrétienté. La société monténégrine est jusqu'au XVIII ème siècle tribale, avec son jeu d'alliances en fonction d'intérêts particuliers. L'évolution des frontières du Monténégro montre que les identités, comme ailleurs en ce temps (début XIXème siècle) sont tribales ou régionales. C'est la construction de l'État, et les luttes politiques du début du XX ${ }^{\mathrm{ème}}$ siècle qui ont contribué à l'édification nationale. À celles-ci s'est ajoutée la lutte dynastique entre la Serbie (Obrenović / Karađorđević) et le Monténégro (Petrović-Njegoš), sise sur l'héritage de l'Empereur médiéval Dušan,

3 L'auteur présente d'abord l'évolution historique de l'État du Monténégro et les deux conceptions étatiques qui se sont enchevêtrées (à ces conceptions étatiques sont attachées des conceptions identitaires). Vasilije Petrović (1744-1766) veut établir un État monténégrin; Petar I ${ }^{\text {er }}$ (1781-1830) et Petar II Petrović (1830-1851) conçoivent la question monténégrine dans le cadre de la défaite ottomane puis de l'instauration d'un empire chrétien (slave, serbe ou russe); Danilo I ${ }^{\text {er }}$ (1852-1860) reprend les concepts de Vasilije ; Nikola (prince 1860-1910, puis roi 1910-1918) adopte une position évolutive, dépendante des contextes.

4 Défenseur des idées de Vasilije et Danilo, c'est la défaite face à l'Empire ottoman en 1862 qui amène Nikola à redéfinir sa stratégie politique; il signe en 1866 l'accord de défense commune que le prince de Serbie, Mihailo Obrenović, propose (organisation d'insurrections sur les frontières ottomanes et incorporation du Monténégro à la Serbie). Il adopte alors les idées de Petar II Petrović qui percevait les Monténégrins comme serbes et l'État monténégrin comme une partie de l'empire médiéval serbe inconquis. Cette idéologie doit être mise en perspective avec l'idéologie nationale française et italienne d'un État/une nation (Nikola a été éduqué à Paris).

5 L'agrandissement territorial accordé par le Traité de San Stefano incite une centralisation de l'État. Elle se heurte à la peur des dirigeants tribaux d'être marginalisés et elle est perçue par la Serbie comme l'établissement d'une dynastie rivale et la remise en cause du rôle de Piémont qu'elle entend jouer dans la sud-slavité. Les conséquences en sont le renforcement de la sécurité au Monténégro, par crainte d'attaques terroristes serbes et l'annonce du couronnement du Prince Nikola, qui insiste sur l'importance de la souveraineté du Monténégro.

6 L'auteur s'attache ensuite au rôle du Monténégro dans la Première Guerre mondiale. Les manœuvres diplomatiques de l'Autriche-Hongrie pour s'assurer de la neutralité du Monténégro dans la Guerre proclamée contre la Serbie se heurtent à la volonté royale d'expansion territoriale afin de négocier plus tard avec la Serbie une alliance dans la domination sud-slave, de s'assurer une indépendance économique, et d'éviter de s'aliéner la population pro-serbe; en outre, ces manœuvres ont pour corollaire le soutien russe à la Serbie. En vertu de l'accord militaire avec la Serbie, c'est le Haut Commandement serbe qui est en charge des opérations militaires (et donc de l'affectation des finances, des rations et de l'équipement, avec l'accord des Alliés). Certains hauts officiers monténégrins font état des sentiments unionistes des officiers serbes $^{1}$. Mais le Monténégro est isolé, et afin d'être en position de négocier, les officiers militaires tentent de satisfaire leurs propres buts militaires, engendrant le discrédit de l'État auprès des Puissances européennes (notamment suite à la prise de Scutari 
[Skadar / Shköder]). Le manque de nourriture et d'armes a raison de l'armée monténégrine. Le gouvernement propose un accord de paix lorsque Cetinje est aux mains des troupes austro-hongroises, le 13 janvier 1916. Les causes de la capitulation monténégrine font l'objet de débats historiques (responsabilité du Roi et de ses visées dynastiques sur la région; responsabilité de la Serbie qui a tout fait pour mettre l'armée monténégrine en première ligne). Marginalisé, Nikola n'obtient pas d'écho à sa demande de soutien pour l'indépendance du Royaume. C'est même le comité monténégrin pour l'unification des territoires serbes qui est l'interlocuteur privilégié. Par ailleurs, le principe de nationalité, mis en avant par la France, s'efface devant le pragmatisme économique (préserver l'Empire ottoman) et c'est l'union d'un État slave que la France soutient désormais,

7 L'auteur passe en revue les actions du Comité monténégrin pour l'Unification en vue de l'annexion du Monténégro ; il décrit le mode de constitution et de fonctionnement de l'Assemblée de Podgorica et les activités du Roi Nikola; il mentionne les blocus de l'armée serbe au Monténégro pour empêcher le retour d'officiers au pays et les plaintes émises par certaines populations au sujet des références constantes à la Serbie. La résolution de l'Assemblée ne fait aucune référence à la Yougoslavie ou l'union slave, mais unit le Monténégro à la Serbie sous la dynastie Karađorđević.

8 L'auteur revient sur le soulèvement de Noël 1919 (janvier) survenu en réaction à cette proclamation qui s'est prolongé, sporadiquement, sur cinq ans (jusqu'en 1924), même si l'essentiel des combats s'est déroulé du 5 au 18 janvier 1919, et présente les deux versions des faits (avec les chiffres de chacune).

9 À n'en pas douter, l'annexion du Monténégro a eu une incidence sur la perception par les autres États sud-slaves de la signification de la création de l'État commun et la perception de la Yougoslavie comme une extension de la Serbie dans les dix premières années du nouvel État. Cet ouvrage remet en perspective l'historiographie serbe de l'histoire du Monténégro. L'auteur parvient en bonne partie à objectiver son objet d'étude ${ }^{2}$ et à présenter les différents points de vue en opposition sur un sujet majeur de l'histoire monténégrine aux répercussions politiques et nationales conséquentes.

\section{NOTES}

1. Le représentant du Haut commandement monténégrin, le général Jovan Bečir, démissionne le 13 octobre 1914 ; le capitaine de l'armée monténégrine, Radivoje Miloševič, aurait été sollicité en 1915 pour participer à un projet d'assassinat du roi Nikola.

2. Il ne peut toutefois pas s'empêcher de noter que le Vidovdan est «le jour le plus sacré du calendrier mythologiquement saturé du nationalisme serbe " (p. 65). Mais on est très loin de l'antiserbisme présent dans Rotković (Radoslav), Velika zavjera protiv Crne Gore (Podgorica: Crnogorska izdanja, 2001), qui est une réponse épidermique aux histoires serbes du Monténégro. 